\title{
EFFECTS OF AIR VELOCITY AND CLOTHING COMBINATION ON HEATING EFFICIENCY OF AN ELECTRICALLY HEATED VEST (EHV): A PILOT STUDY
}

\author{
Faming Wang, Chuansi Gao, and Ingvar Holmér \\ Thermal Environment Laboratory, Division of Ergonomics and Aerosol Technology, \\ Department of Design Sciences, Faculty of Engineering, Lund University, Lund, 221 00, \\ Sweden
}

Contact person: faming.wang@ design.lth.se

\section{INTRODUCTION}

Modern fibre and textile materials and miniaturized electronic components make the implementation of smart garments that enhance the functionality of the ordinary clothing possible. One of the typical smart garments used in the cold condition is the electrically heated vest (EHV). The main functions of an EHV are heating the torso part of the human body and helping the human torso body against the cold stresses in cold environments. The heating elements can be metallic heating wires, graphite elements, electrically conductive rubber, neutralized textile fabrics, positive temperature coefficient polymers or a system of water heaters $[1,2]$. However, these heating elements might limit the human activity to some extent. Recently, a kind of new carbon polymer heating element was successfully developed and launched in the market. The carbon polymer heating elements are slim, light and washable, and most important, there is no limitation on the human movement.

Previous studies [3-5] have proved that the heating efficiency and heating power are the two most important parameters that should be considered during the EHV design process. In this article, we studied the effects of air velocity and clothing combination on the heating efficiency in the cold environment by a thermal manikin. The temperature distribution on the EHV was measured by an infrared thermal camera. In addition, the theoretical results were finally analyzed and some suggestions for the usability of the EHV were finally projected.

\section{METHODOLOGY}

\section{CLOTHING ENSEMBLE TESTED}

A pair of military uniforms, knit cotton underwear, an EHV, a pair of thick polyamide stockings, a pair of sports shoes and a pair of thick gloves was used in the tests. The details of these garments are described in Table 1 . Three clothing combinations were chosen: $\mathrm{E}+\mathrm{U}+\mathrm{M}$, $\mathrm{U}+\mathrm{E}+\mathrm{M}$ and $\mathrm{U}+\mathrm{M}+\mathrm{E}$ (the three codes in the clothing combination stand for an inner layer $+\mathrm{a}$ middle layer + an outer layer), where EHV was worn as inner, middle, and outer layer respectively.

Table 1 Details of the clothing ensembles

\begin{tabular}{cc}
\hline \multicolumn{2}{c}{ Clothing ensemble } \\
$\begin{array}{c}\text { Knit underwear } \\
\text { (code: } \mathrm{U})\end{array}$ & $\begin{array}{c}\text { Color: darkolivegreen } \\
\text { weight: } 624 \mathrm{~g} \\
\text { material: cotton }\end{array}$ \\
\hline
\end{tabular}




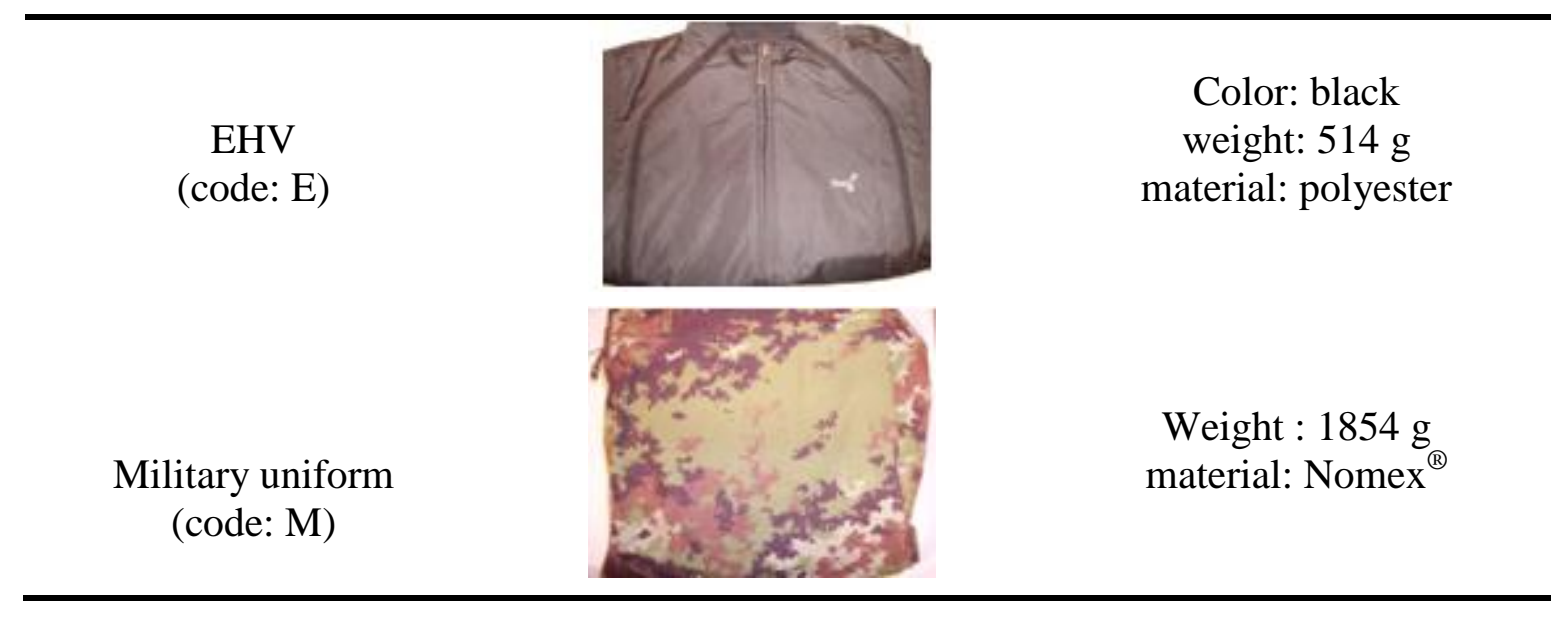

Six strips of the carbon polymer heating elements were applied to the front and back sacks of a woven vest. The size of the heating element strip is $155 \times 52 \times 0.82 \mathrm{~mm}$, and the weight is about $16 \mathrm{~g}$. The total heating area accounts for about $8.5 \%$ of the total torso surface area. The locations of the heating elements inside the vest are shown in Fig. 1. A nine-volt power box was used as the main power for this EHV. The heating current can be easily obtained from the Liquid Crystal Display (LCD) on the power box.

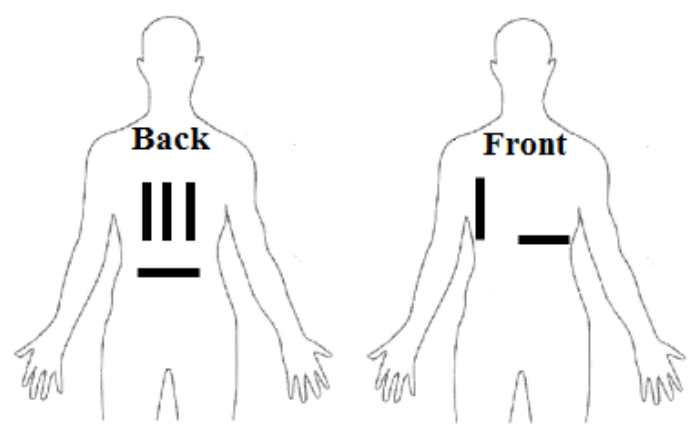

Fig.1 The locations of the carbon polymer heating elements inside the sacks of an EHV.

\section{THERMAL MANIKIN}

A Swedish 17-section standing thermal manikin Tore was used in the tests. Tore is made of plastic with a metal frame inside to support body parts and for joints [6]. It has the size of an average Swedish male of the 1980s. Its height is $170 \mathrm{~cm}$, chest and waist circumference 94 $\mathrm{cm}$ and $88 \mathrm{~cm}$ respectively, with total heated body area of $1.774 \mathrm{~m}^{2}$. Tore weighs $33 \mathrm{~kg}$ and that makes it easy to handle. The whole thermal manikin system was placed in a climatic chamber, where various environmental conditions can be simulated. With this manikin, the heating power to keep constant skin surface temperature of each zone and the temperatures are controlled and recorded continuously by the system program.

\section{TEST PROCEDURES}

The thermal manikin skin surface temperature was set at $34{ }^{\circ} \mathrm{C}$ to simulate the human body in the comfortable condition. All the tests were conducted at an air temperature of $4.5^{\circ} \mathrm{C}$ and the relative humidity is $85 \%$. For the air velocity, three levels were chosen: $0.22 \pm 0.02$ $\mathrm{m} / \mathrm{s}, 0.44 \pm 0.02 \mathrm{~m} / \mathrm{s}$ and $0.66 \pm 0.02 \mathrm{~m} / \mathrm{s}$. A FLIR T200 infrared thermal camera was used to measure the surface temperature of the EHV in the clothing ensemble. 
The area weighted heat losses of the typical three-layer clothing ensemble can be directly obtained by the test report system for the thermal manikin Tore. The heating output power for the EHV can be calculated by the heating voltage and current from the power box. Then the heating efficiency of an EHV is defined as [7]

$$
\eta=\frac{H L_{\text {area }}}{P k}
$$

where, $H L_{\text {area }}$ is the area weighted heat loss from the torso part (for thermal manikin Tore, it has 4 zones, including the chest, abdomen, back and buttocks) of the thermal manikin (W); $P$ is the output power of the power box (W) to the heating elements; $k$ is the energy convert rate of the heating element $(\%)$, for the carbon polymer heating element used in the experiment, the convert rate is set to $90 \%$.

\section{RESULTS}

The torso heat losses at various air velocities and clothing combinations were directly obtained by the manikin system program. A current of $1.45 \mathrm{~A}$ was observed from the power box. The heating power of the EHV was $13.05 \mathrm{~W}$ accordingly. Then the heating efficiencies of the EHV can be easily calculated, the results are shown in Fig. 2. The statistical regression curves were also drawn according to the final heating efficiency results.

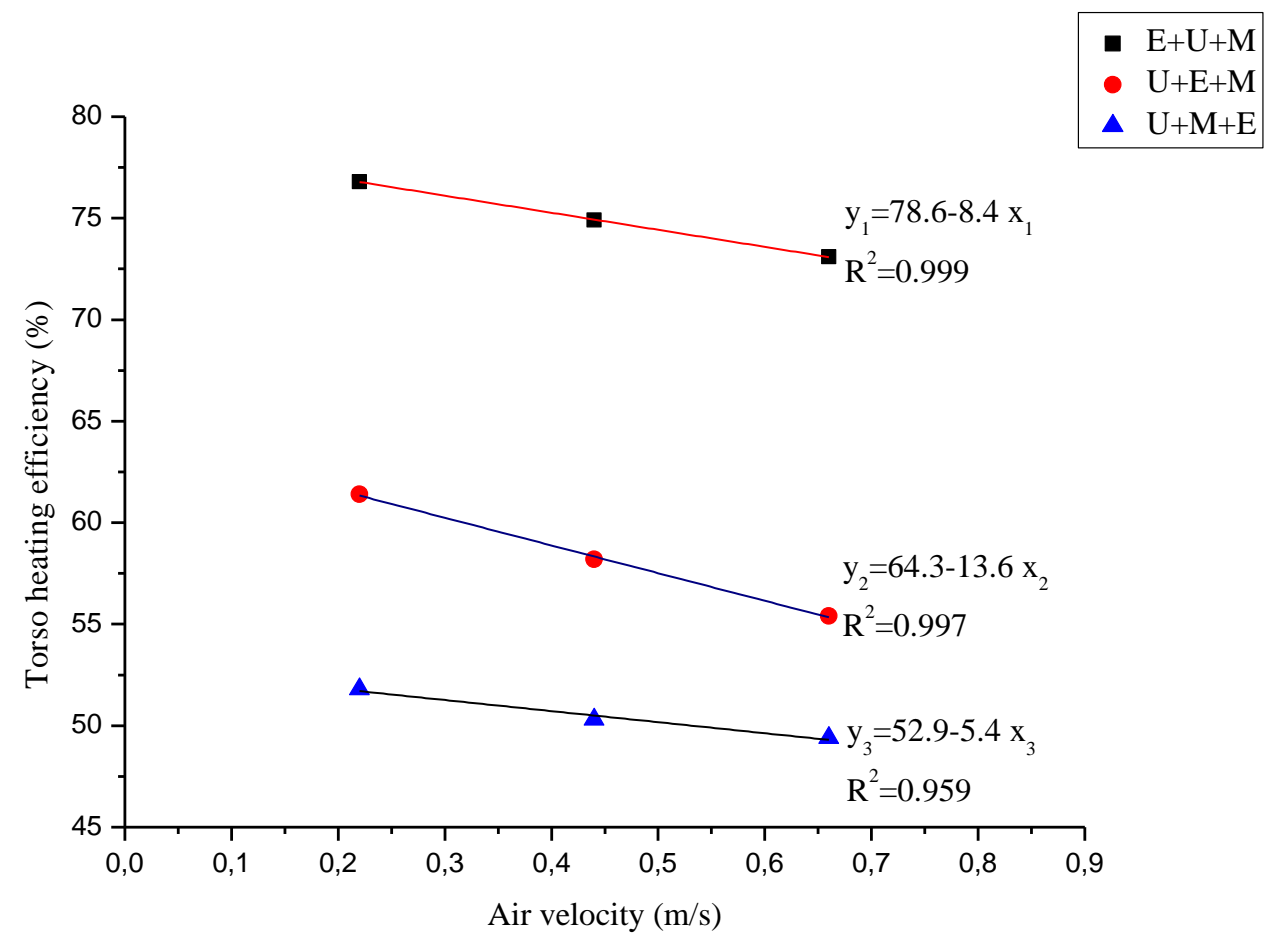

Fig.2 Effect of the air velocity on the torso heating efficiency.

It can be easily seen that the relationship between the air velocity and heating efficiency of different clothing combinations is linear within the tested short air velocity interval. The maximal heating efficiency at $0.22 \mathrm{~m} / \mathrm{s}$ was much higher than the values obtained at higher air speed, e.g. $0.44 \mathrm{~m} / \mathrm{s}$ and $0.66 \mathrm{~m} / \mathrm{s}$. This can be explained by higher air velocity makes more heat from the EHV dissipated to the environment. 
The maximum theoretical heating efficiencies of the EHV in the clothing combinations $\mathrm{E}+\mathrm{U}+\mathrm{M}, \mathrm{U}+\mathrm{E}+\mathrm{M}$ and $\mathrm{U}+\mathrm{M}+\mathrm{E}$ calculated according to above regression equations (assuming the air velocity is $0 \mathrm{~m} / \mathrm{s}$ ) are $78.6 \%, 64.3 \%$ and $52.9 \%$ respectively. It can be deduced from Fig. 3 that the EHV has the best heating efficiency when it was served as an inner layer in the three-layer clothing ensemble. As expected, the EHV has the lowest heating efficiency when served as an outer layer. This is due to layers outside of the EHV provide an efficient thermal insulation to avoid losing too much heat from the EHV to the environments. Hence, it is suggested that the EHV should be worn as an inner or middle layer to make heating the human body more effective.

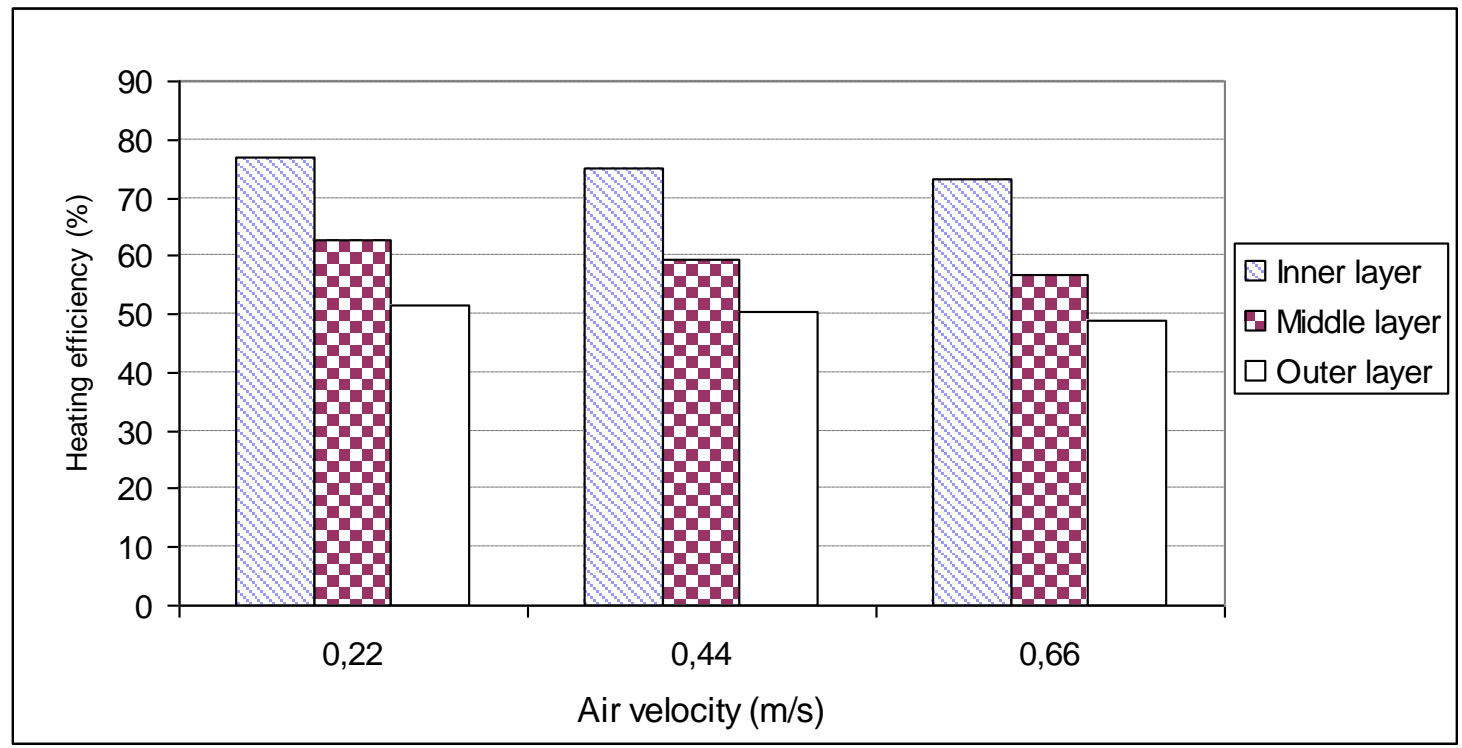

Fig.3 Effect of the clothing combinations on the torso heating efficiency.

\section{INFRARED THERMOGRAPHY}

The thermogram images were analyzed by the FLIR ${ }^{\circledR}$ Researcher Program. Fig. 4 shows the representative thermogram images of the EHV at its front and back views for the clothing combination E+U+M. In Fig. 4 (a), the highest temperatures of the EHV outer layer material above two heating element strips are 24 and $25.5^{\circ} \mathrm{C}$ respectively. Fig. 4 (b) presents the back side temperature distribution of the EHV. It can be seen that the highest temperatures above the three heating elements are $26.5,24.8$ and $26.5^{\circ} \mathrm{C}$ respectively. The temperature at the part without heating element is much lower, e.g. the point temperature on the upper back is 14.2 ${ }^{\circ} \mathrm{C}$, and the maximum temperature on the front area of the EHV is $32.2^{\circ} \mathrm{C}$. Consequently, the EHV is especially suitable for the wearers in light activities (normally below $2.0 \mathrm{Met}$ ) [8].

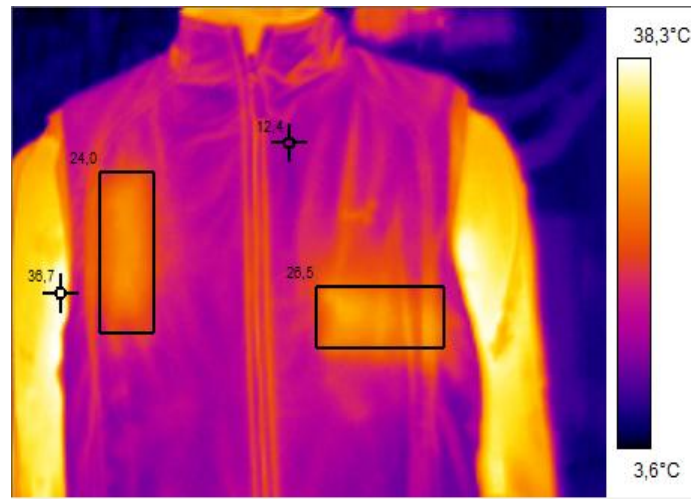

(a)

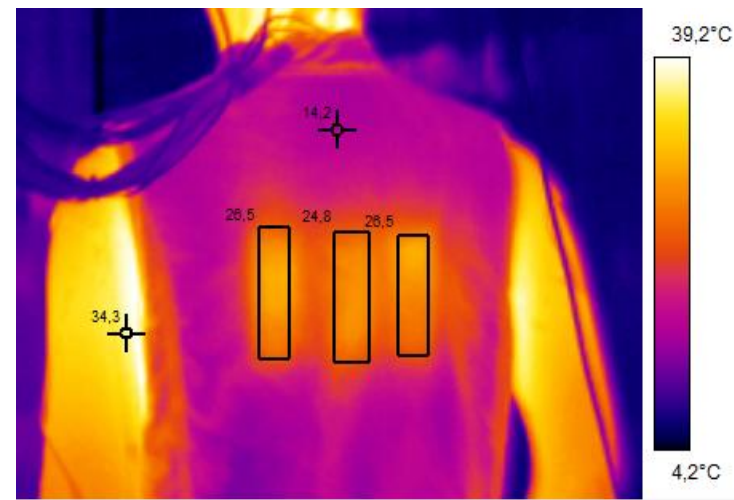

(b) 
Fig. 4. Infrared thermographs of the EHV in the clothing combination E+U+M. (a) the front side; (b) the back side.

\section{CONCLUSIONS}

This study presents a novel method based on a thermal manikin to investigate the effect of air velocity and clothing combinations on the heating efficiency of an EHV in a cold environment. The result showed that the air velocity can linearly decrease the heating efficiency. It was also found that the EHV has the highest heating efficiency when it was served as the inner layer in the three-layer clothing ensemble. However, the EHV might not be suitable to be worn as an inner layer due to that the woven vest might affect the wearing comfort. Moreover, the initial intention of making these EHVs is to protect human upper body by wearing them as an additional garment piece over the underwear or jacket. Hence, the EHV can be recommended to be worn as a middle layer not only because of the consideration of thermal comfort but also for saving energy and making the heating more effective.

\section{ACKNOWLEDGEMENTS}

This work is supported by the China Scholarship Council (CSC) and Taiga Co. Ltd in Varberg, Sweden. The authors appreciate Dr. Kalev Kuklane for his valuable comments.

\section{REFERENCES}

1. W. Wiezlak, and J. Zielinski. Clothing heated with textile heating elements, Int J Cloth Sci Tech 1993; 5: 9-21.

2. M. F. Haisman. Physiological aspects of electrically heated garments, Ergonomics 1988; 31: 1049-1063.

3. K. Kukkonen, T. Vuorela, J. Rantanen, O. Ryynänen, and A. Siili et al. The design and implementation of electrically heated clothing, Proc Int Symp Wear Comput 2001; 180-181.

4. T. Risikko, and H. Anttonen. Use of personal heaters in cold work. Problems with cold work, In. Ingvar Holmér and Kalev Kuklane (ed.) 1998; 29-30.

5. D. Brajkovic, M. B. Ducharme, and J. Frim. Influence of localized auxiliary heating on hand comfort during cold exposure, J Appl Physiol 1998; 85: 2054-2065.

6. K. Kuklane, S. Heidmets, and T. Johansson. Improving thermal comfort in an orthopaedic aid: better Boston brace for scoliosis patients, Proc Int Meet Therm Mani Model 2006, In. Jintu Fan (ed.) 2006; 345-346.

7. F. Wang, S. Hwang, and H. Lee. Evaluation of an electrically heated vest (EHV) on thermal manikin under two different cold environments. Manuscript submitted for publication 2009.

8. ISO 7933. Ergonomics of the thermal environment--- Analytical determination and interpretation of heat stress using calculation of the predicted heat strain. International Organization for Standardization, Geneva, Switzerland, 2004. 